\title{
RIZOBACTÉRIA E POLIMERO APLICADOS EM SEMENTES DE Jacaranda mimosifolia D. Don PROMOVEM O CRESCIMENTO DAS MUDAS
}

\author{
Evandro Luiz Missio ${ }^{1}$ \\ 1-Pesquisador Doutor da Fundação Estadual de Pesquisa Agropecuária, Centro de \\ Pesquisa em Florestas, Santa Maria, RS, Brasil - evandro@fepagro.rs.gov.br. \\ Recebido em: 05/12/2016 - Aprovado em: 15/12/2016 - Publicado em: 31/12/2016 \\ DOI: 10.18677/Agrarian_Academy_2016b10
}

Jacaranda mimosifolia é uma espécie florestal de ocorrência em vários países da América do Sul, produzida com frequência em viveiros florestais. Sua propagação ocorre via semente, a qual geralmente apresenta boa germinação, porém, a interferência de fatores bióticos e abióticos muitas vezes afeta esta etapa no viveiro. O objetivo deste trabalho foi avaliar o crescimento de mudas de J. mimosifolia provenientes de sementes tratadas com rizobactéria e polímero. Foram elaborados quatro tratamentos em delineamento inteiramente casualizado, representados por biopromotor (Bacillus subtilis e testemunha) e peliculização (polímero e testemunha). Aos 60 e 120 dias após a emergência (DAE) foi avaliada a altura da parte aérea, diâmetro do coleto e razão altura/diâmetro. Também, aos 120 DAE, foram medidos o volume radicular massa seca da parte aérea, raiz e total, e razão entre a massa seca da parte aérea/raízes. $O$ tratamento de sementes com $B$. subtilis e polímero resultou em maior altura da parte aérea das mudas aos 60 e $120 \mathrm{DAE}$, diâmetro do coleto superior (60 DAE) e igual à testemunha (120 DAE), maior volume radicular, além de massa seca da parte aérea e total estatisticamente igual à testemunha. Através destes resultados permite-se concluir que: o tratamento de sementes de $\mathrm{J}$. mimosifolia com $B$. subtilis e polímero promovem o crescimento das mudas; a aplicação de $B$. subtilis associada a polímero em sementes de J. mimosifolia é uma técnica eficiente para a produção de mudas em viveiro.

PALAVRAS-CHAVE:: Bacillus subtilis; biopromotor; produção de mudas.

\section{RHIZOBACTERIAL AND POLYMERS APPLIED IN Jacaranda mimosifolia D. Don SEEDS PROMOTE THE SEEDLINGS GROWTH}

\begin{abstract}
Jacaranda mimosifolia is a forest species of occurrence in several countries of South America, often produced in forest nurseries. Its propagation occurs via seed, which usually presents good germination, however, the interference of biotic and abiotic factors often affects this stage in the nursery. The objective of this work was to evaluate the growth of $\mathrm{J}$. mimosifolia elaborated in a completely randomized design, represented by biopromotor (Bacillus subtilis and control) and peliculization (polymer and control). At 60 and 120 days after emergence (DAE) the shoot height, collection diameter and height / diameter ratio were evaluated. Also, at $120 \mathrm{DAE}$, the root dry mass of root, total and root dry mass and root dry mass ratio were measured. Seed treatment with $B$. subtilis and polymer resulted in a higher shoot height at 60 and 120
\end{abstract}


DAE, higher collection diameter (60 DAE) and equal to control (120 DAE), higher root volume, as well as dry mass Of the aerial part and total statistically equal to the control. Through these results it is possible to conclude that: treatment of seed of $J$. mimosifolia with $B$. subtilis and polymer promotes seedling growth; The application of polymer associated $B$. subtilis in seeds of $\mathrm{J}$. mimosifolia is an efficient technique for the production of nursery seedlings.

KEYWORDS: Bacillus subtilis, biopromoter, Seedlings production.

\section{INTRODUÇÃO}

Jacaranda mimosifolia é uma espécie arbórea pertencente à família Bignoniaceae com distribuição em diferentes países sul-americanos. É utilizada para arborização urbana devido ao florescimento exuberante, bem como potencial madeireiro para fins de marcenaria. Sua multiplicação ocorre por sementes, as quais apresentam produção ao longo do ano (LORENZI, 2003).

Esta espécie pode ser propagada em viveiro, porém, as mudas podem apresentar crescimento reduzido pela influência de fatores bióticos e abióticos. Dentre os problemas fitossanitários que podem ocorrer em viveiros florestais, as doenças causadas por fungos são as mais comuns e as mais importantes. Condição sanitária da semente, fatores abióticos, assepsia das ferramentas, substrato, entre outros, podem contribuir para a contaminação (CARNEIRO, 1972). Mais especificamente, o tipo de substrato muitas vezes pode não favorecer o crescimento das mudas, devido às características químicas e físicas do composto.

Neste contexto, estudos envolvendo o uso de microrganismos promotores de crescimento de plantas podem contribuir no sentido de qualificar a produção de mudas de J. mimosifolia, assim como de outras espécies florestais. Segundo SIVASAKTHI et al. (2013) o uso de rizobactérias possui potencial para a promoção do crescimento em plantas. Dentre estas, destaca-se $B$. subtilis, a qual possui a capacidade de sintetizar fitohormônios, como ácido indolacético, ácido abscísico, giberelinas e citocininas, os quais favorecem a formação de pêlos radiculares, aumentando o volume radicular (ARAÚJO \& HUNGRIA, 1999). Também estimula a síntese de metabólitos responsáveis pela melhor percepção do sistema radicular às condições do meio, favorecendo a absorção de nutrientes para a planta (MANJULA \& PODILE, 2005).

O uso de bactérias do gênero Bacillus possui menção em espécies anuais de interesse econômico, além de arbóreas florestais. Para aquelas anuais, existem resultados positivos no estímulo ao crescimento em Phaseolus vulgaris (LAZARETTI \& MELO, 2005), Brachiaria decumbens, B. brizantha e Panicum maximum (ARAÚJO \& PEDROSO, 2013), Lactuca sativa (GUIMARÃRES et al., 2013), Hibiscus esculentus (MAQBOOL et al., 2015) e Saccharum spp. (SANTOS \& ROGOBELO, 2016). Para as arbóreas também são encontradas informações relacionando promoção de crescimento de $B$. subtilis em propágulos de Eucalyptus sp. (TEIXEIRA et al., 2007; RAASCH et al., 2013; MARQUES \& UERUGI, 2013), Caesalpinia apeltophoroides (CUNHA et al., 2013) e Theobroma cacao (LEITE et al., 2013). Também são encontrados trabalhos que mostraram não haver influência no crescimento de mudas de Parapiptadenia rigida através da aplicação de $B$. subtilis via semente (MISSIO \& MORO, 2016).

Outra tecnologia, a peliculização de sementes, bastante utilizada no tratamento de sementes de espécies comerciais, também é uma alternativa com potencial para ser testada em sementes florestais. Em nível comercial, existem produtos à base de filme "coatings" chamados de películas, os quais aplicados à 
semente formam uma fina camada sem causar mudanças no seu tamanho ou forma (TAYLOR et al., 1997). Uma das características deste filme é melhorar e prolongar a ação de outros produtos que são aplicados simultaneamente às sementes (SAMPAIO \& SAMPAIO, 1994). Entretanto, o sucesso da peliculização dependerá da natureza do filme polimérico e das características da espécie em estudo (TRENTINI et al., 2005).

$\mathrm{Na}$ literatura são encontradas informações sobre a peliculização associada a diferentes produtos químicos em sementes de Lactuca sativa (DINIZ et al., 2006), Crambe abyssinica (LUDWIG et al., 2014) e Solanum lycopersicum (MELO et al., 2014; MELO et al., 2015). Quanto à associação entre películas e microrganismos promotores de crescimento vegetal, existem referências recentes mostrando resultados em sementes de culturas anuais como Zea mays (JUNGES et al., 2013; JUNGES et al., 2014) e Daucus carota (PEDROSO et al., 2014), além de informações para a espécie arbórea Parapiptadenia rigida (MISSIO \& MORO, 2016). Entretanto, existe muita carência de informação envolvendo essa associação, especialmente em espécies florestais.

O presente trabalho teve como objetivo avaliar o crescimento de mudas de $\mathrm{J}$. mimosifolia provenientes de sementes tratadas com rizobactéria e polímero.

\section{MATERIAL E MÉTODOS}

Para a realização do trabalho, foram utilizadas sementes de J. mimosifolia coletadas de cinco matrizes localizadas no Município de Itaara/RS (2933'39,73"S; 53\%6'4,16"O) no ano de 2014. O material foi benefi ciado e em seguida efetuado as determinações (BRASIL, 2013), de pureza (99 \%), umidade (12\%), peso de mil sementes (9,30 gramas) e germinação (80 \%).

Foram avaliados 16 tratamentos, arranjados em esquema fatorial $(2 \times 2)$, representados por biopromotor (Bacillus subtilis e testemunha), peliculização (polímero e testemunha), com quatro repetições, em delineamento inteiramente casualizado.

Os tratamentos foram compostos por quatro tratamentos descritos da seguinte forma: T1 - testemunha geral (sem biocontrolador e sem polímero); T2 testemunha de biocontrolador + polímero; T3 - biocontrolador sem polímero; T4 biocontrolador + polímero. Para aplicação dos tratamentos foram utilizados produtos comerciais com as seguintes dosagens para cada 200 sementes: $B$. subtilis (Rizolyptus ${ }^{\circledR}$ )- $4 \mathrm{~mL}$ de produto; Polímero (PolySeed $70^{\circledR}$ )- $2 \mathrm{~mL}$.

Para aplicação dos produtos, as sementes foram postas em caixas do tipo gerbox e em seguida imersas na solução referente a cada tratamento. Após, foi retirado o excesso do produto e imediatamente levadas para o viveiro, onde foram semeadas em recipientes do tipo tubetes cônicos de polipropileno, com capacidade para $90 \mathrm{~cm}^{3}$ de substrato. O raleio foi realizado 15 dias após a emergência mantendo-se as mudas com posição mais central e com melhor desenvolvimento. $O$ término do experimento ocorreu aos 120 dias após a emergência. Cada repetição foi formada por 10 tubetes, totalizando 40 tubetes por tratamento. Foram efetuados casualizações e rodízios semanais.

O substrato utilizado foi formado a partir da mistura de $40 \%$ solo, $40 \%$ de esterco bovino e $20 \%$ de casca de arroz carbonizada. O solo utilizado foi caracterizado como Argissolo vermelho Distrófico arênico (EMBRAPA, 2013), sendo a fração de uso extraída do horizonte $A$.

Foram efetuadas avaliações de crescimento aos 60 e 120 dias após a emergência (DAE onde foram coletadas as seguintes variáveis: a) altura da parte 
aérea $(\mathrm{H})$ - determinada entre a região do colo da muda até a inserção da última folha, com auxílio de uma régua; b) diâmetro do coleto (D) - medido a um $\mathrm{cm}$ acima da região do colo da planta com uso de um paquímetro; c) razão entre altura da parte aérea e diâmetro do coleto $(\mathrm{RH} / \mathrm{D})$ - obtido pela divisão entre as partes; $d$ ) volume radicular - as raízes das plantas de cada repetição foram postas em uma proveta contendo água e, por diferença entre o volume inicial e final, obtidos os resultados. Após as leituras de crescimento, aos 120 DAE, as plantas foram excisadas na região do colo, ao nível do substrato, e posteriormente separados raízes de parte aérea. O sistema radicular foi lavado em água corrente para a retirada do substrato. Todo o material foi levado para estufa com ar forçado e temperatura de $65^{\circ} \mathrm{C}$ até peso constante. Posteriormente foram determinados o peso de massa seca da parte aérea (MSPA) e peso da massa seca do sistema radicular (MSR). O peso da massa seca total (MST) foi calculado com base na soma do MSPA e MSR. Por fim, foi analisada a relação entre o peso de matéria seca da parte aérea e o peso de matéria seca do sistema radicular (RMSPA/MSR). Para todas as pesagens foi utilizada uma balança de precisão com três casas decimais, sendo o resultado expresso em gramas por planta.

Os dados foram submetidos à análise da variância e posteriormente ao teste de Tukey ao nível de 5\% de probabilidade.

\section{RESULTADOS E DISCUSSÃO}

O tratamento das sementes de J. mimosifolia mostrou diferenças significativas no crescimento das mudas. Na avaliação de 60 dias após a emergência (60 DAE), a altura da parte aérea foi maior nas sementes tratadas com $B$. subtilis e polímero, diferindo estatisticamente dos tratamentos envolvendo somente aplicação do biopromotor, bem como aquele que recebeu somente a peliculização. A associação entre $B$. subtilis e polímero resultou em crescimento $14 \%$ superior às mudas provenientes de sementes que receberam o microrganismo sem a película, e 11\% superior a aquelas em que foi usado somente polímero nas sementes (Tabela 1).

Novamente aos 120 DAE, houve comportamento semelhante ao da primeira avaliação, onde as sementes tratadas com $B$. subtilis e polímero mantiveram as mudas com crescimento significativo aos demais tratamentos, resultando em ganhos $10 \%$ superiores ao tratamento com somente biopromotor, e 11,3\% superior ao tratamento com somente polímero (Tabela 1). Embora não possa ser efetuada a comparação estatística entre o melhor tratamento ( $B$. subtilis e polímero) e a testemunha geral, que não recebeu tratamento de sementes nota-se que aos 60 DAE e 120 DAE, o ganho em altura da parte aérea foi $18 \%$ e $11 \%$ superior, respectivamente.

As informações referentes à altura da parte aérea evidenciam que a associação entre $B$. subtilis e polímero, via semente, contribuiu positivamente para o crescimento de plantas de $\mathrm{J}$. mimosifolia. A película favoreceu a ação da rizobactéria ao longo do tempo, permitindo uma associação mais bem sucedida entre as raízes da planta e $B$. subtilis do que somente a aplicação isolada do biopromotor nas sementes. Outra constatação, é que esta bactéria, biopromotora de crescimento, pode ser inoculada via semente para posteriormente colonizar o substrato visando à produção de mudas de J. mimosifolia, porém, as condições deste trabalho mostraram a necessidade da associação com um filme polimérico para obtenção de resultados satisfatórios.

Estudos desenvolvidos por SIVASAKTHI et al. (2013), mostraram o potencial que isolados de $B$. subtilis tiveram sobre a promoção de crescimento de Oryza 
sativa, através da capacidade que o microrganismo possuiu de solubilizar fosfato para as raízes da planta. A exemplo do que ocorreu neste trabalho, JUNGES et al. (2013) também observaram efeito positivo da aplicação de $B$. subtilis e polímero em sementes de Zea mays, onde foi constatado que houve estímulo ao crescimento das plântulas. Contudo, um estudo semelhante desenvolvido por MISSIO \& MORO (2016), com sementes da espécie florestal Parapiptadenia rigida tratadas com $B$. subtilis e polímero, mostrou não haver contribuição no crescimento da parte aérea das mudas. Segundo estes autores, as características da espécie e metodologia utilizada no trabalho podem ter influenciado na associação entre a rizobactéria e a planta.

TABELA 1 Altura da parte aérea de mudas de J. mimosifolia aos 60 e 120 dias após a emergência (DAE) provenientes de diferentes tratamentos aplicados às sementes. Santa Maria-RS, 2016.

\begin{tabular}{lll}
\hline \multicolumn{3}{c}{ 60 DAE } \\
\hline Biopromotor & \multicolumn{1}{c}{ Polímero } \\
\hline B. subtilis & Com Polimero & Sem Polimero \\
Testemunha & $15,82 \mathrm{Aa}^{*}$ & $13,97 \mathrm{Ba}$ \\
\hline CV $(\%)$ & $13,51 \mathrm{Ab}$ & $12,94 \mathrm{Ab}$ \\
\hline \multicolumn{4}{c}{$\mathbf{1 2 0}$ DAE } \\
\hline B. subtilis & 6,63 & $16,30 \mathrm{Ba}$ \\
Testemunha & $17,93 \mathrm{Aa}$ & $15,88 \mathrm{Aa}$ \\
\hline \multicolumn{1}{c}{ CV $(\%)$} & $15,89 \mathrm{Ab}$ & \\
\hline
\end{tabular}

${ }^{*}$ Médias seguidas de mesmas letras, maiúsculas na linha e minúsculas na coluna, não diferem entre si pelo teste de Tukey a $5 \%$.

O diâmetro do coleto das mudas de J. mimosifolia mostrou comportamento distinto para as duas épocas de avaliação (Tabela 2). Aos 60 DAE, o tratamento de sementes com $B$. subtilis associado a peliculização foi o mais eficiente para 0 incremento do diâmetro das mudas, apresentando aumento significativo de 7,4\% quando comparado com o tratamento que recebeu somente polímero. Com relação à presença ou ausência de polímero junto a $B$. subtilis, não foram observadas diferenças entre as médias. Entretanto, este cenário mudou na segunda avaliação aos $120 \mathrm{DAE}$, onde as sementes tratadas com a rizobactéria associada à peliculização produziram diâmetro de coleto significativamente inferior à testemunha do biopromotor com polímero. Apesar disso, o resultado geral para as duas épocas pode ser considerado satisfatório, pois agrupando estas informações com aquelas obtidas para a altura da parte aérea, infere-se que associação entre o biopromotor e as raízes das plantas é potencialmente favorável para o aumento do diâmetro do coleto das mudas, até porque o microrganismo está presente na rizosfera das plantas e mostrou que houve um processo de associação com a planta. Segundo MOREIRA \& ARAÚJO (2013), a inoculação de rizobactérias em espécies florestais pode proporcionar ganhos consideráveis no desenvolvimento das plantas.

A altura da parte aérea e o diâmetro do coleto são variáveis importantes quando se objetiva padrão de qualidade de mudas. Segundo HAASE et al. (2006), são os parâmetros morfológicos mais utilizados para expressar a qualidade de mudas. Esta informação reforça a importância de estudos envolvendo técnicas e metodologias que permitam a expressão de padrões de qualidade nas mudas produzidas em escala comercial. No caso de J. mimosifolia, a associação entre $B$. 
subtilis e polímero, aplicados às sementes, podem fazer com que tais padrões sejam alcançados ao longo do ciclo de produção no viveiro.

TABELA 2 Diâmetro do coleto de mudas de J. mimosifolia aos 60 e 120 dias após a emergência (DAE) provenientes de diferentes tratamentos aplicados às sementes. Santa Maria-RS, 2016.

\begin{tabular}{|c|c|c|}
\hline \multicolumn{3}{|c|}{60 DAE } \\
\hline Biopromotor & \multicolumn{2}{|c|}{ Polímero } \\
\hline & Com Polimero & Sem Polimero \\
\hline B. subtilis & $2,55 \mathrm{Aa}^{*}$ & $2,51 \mathrm{Aa}$ \\
\hline Testemunha & $2,36 \mathrm{Ab}$ & $2,15 \mathrm{Bb}$ \\
\hline CV (\%) & 6,50 & \\
\hline \multicolumn{3}{|c|}{120 DAE } \\
\hline B. subtilis & $3,83 A b$ & $3,85 \mathrm{Aa}$ \\
\hline Testemunha & $4,09 A a$ & $3,91 \mathrm{Ba}$ \\
\hline CV (\%) & 5,33 & \\
\hline
\end{tabular}

*Médias seguidas de mesmas letras, maiúsculas na linha e minúsculas na coluna, não diferem entre si pelo teste de Tukey a $5 \%$.

A razão entre altura da parte aérea e diâmetro do coleto das mudas mostrou as maiores amplitudes nas mudas provenientes de sementes que foram tratadas somente com $B$. subtilis. Porém, este resultado não expressou diferenças estatísticas em relação às mudas com o biopromotor associado ao polímero, e testemunha do microrganismo e polímero (Tabela 3). A menor razão entre altura e diâmetro das mudas foi obtida no tratamento que recebeu somente a película, mostrando um maior equilíbrio entre o crescimento entre as partes.

$O$ volume radicular apresentou maior crescimento em mudas oriundas do tratamento de sementes com $B$. subtilis e polímero, sendo as médias estatisticamente superiores ao tratamento sem biopromotor e com polímero, e também daquele que foi somente aplicado o microrganismo (Tabela 3). A combinação entre $B$. subtilis e polímero resultou num crescimento radicular que chegou a percentuais $46 \%$ superiores ao tratamento que recebeu somente a rizobactéria, $33 \%$ do tratamento no qual as sementes foram somente peliculizadas, e $70 \%$ de crescimento a mais que a testemunha geral que não recebeu nenhum tipo de tratamento. Uma hipótese para este evento pode estar relacionada com as características da película, a qual objetiva prolongar a ação de determinado produto, atuando positivamente para a ação da rizobactéria no substrato, formando um microambiente para que houvesse estímulo ao crescimento radicular por parte do microrganismo.

O estímulo ao crescimento radicular é um dos efeitos benéficos das rizobactérias promotoras de crescimento, as quais favorecem a formação e desenvolvimento das raízes laterais e adventícias, característica considerada benéfica para plantas, pois aumenta a exposição radicular facilitando a fixação de água e nutrientes do meio (MOREIRA \& ARAÚJO, 2013). O estímulo ao crescimento radicular por parte das rizobactérias promotoras de crescimento ocorre devido ao aumento na síntese da enzima ACC desaminase, a qual reduz a ação do etileno no sistema radicular, fito hormônio que dificulta o alongamento das raízes, resultando na formação e desenvolvimento do sistema radicular (PRIGENT-COMBARET et al. 2008, citado por MOREIRA \& ARAÚJO, 2013). 
TABELA 3 Razão entre altura da parte aérea e diâmetro do coleto (Razão H/D) e Volume radicular de mudas de J. mimosifolia aos 120 dias após a emergência (DAE) provenientes de diferentes tratamentos aplicados às sementes. Santa Maria-RS, 2016.

\begin{tabular}{|c|c|c|}
\hline Biopromotor & \multicolumn{2}{|c|}{ Polímero } \\
\hline \multicolumn{3}{|c|}{ Razão H/D } \\
\hline & Com Polimero & Sem Polimero \\
\hline B. subtilis & $4,50 \mathrm{Aa}^{*}$ & $4,61 \mathrm{Aa}$ \\
\hline Testemunha & $4,15 \mathrm{Ab}$ & $4,42 \mathrm{Aa}$ \\
\hline CV (\%) & 9,29 & \\
\hline \multicolumn{3}{|c|}{ Volume Radicular $\left(\mathrm{mL}^{-1}\right)$} \\
\hline B. subtilis & $10,00 \mathrm{Aa}$ & $5,33 \mathrm{Ba}$ \\
\hline Testemunha & $6,66 \mathrm{Ab}$ & $3,00 \mathrm{Bb}$ \\
\hline
\end{tabular}

${ }^{\star}$ Médias seguidas de mesmas letras, maiúsculas na linha e minúsculas na coluna, não diferem entre si pelo teste de Tukey a $5 \%$.

A aplicação de $B$. subtilis associado à película promoveu o maior acúmulo de massa seca da parte aérea (MSPA) das mudas de J. mimosifolia (Tabela 4), mostrando valores significativamente superiores $(11,8 \%$ a mais na produção de MSPA) em relação ao tratamento que recebeu somente polímero, e $10 \%$ a mais que as mudas provenientes da aplicação isolada da rizobactéria. Tal resultado se assemelha aquele obtido para a altura da parte aérea, mostrando que a associação entre o microrganismo e polímero foi favorável para o crescimento das mudas. Avaliando o comportamento de dois isolados de Bacillus sp. inoculados em sementes de duas cultivares de Solanum lycopersicum, SZILAGYI-ZECCHIN et al. (2015) constataram que um destes isolados promoveu aumento nos teores clorofila $a, b$ e totais, refletindo em maior crescimento da parte aérea de mudas e, consequentemente, no acúmulo de massa seca das plantas.

Comportamento semelhante foi observado quanto à produção de massa seca das raízes (MSR), onde a rizobactéria juntamente com o polímero, aplicados às sementes, resultaram em plantas com maior volume radicular (Tabela 3), devido a maior estímulo à emissão e crescimento de novas raízes, refletindo em produção de $19,52 \%$ de MSR a mais que o tratamento significativamente inferior (sem biopromotor e com peliculização aplicado às sementes) (Tabela 4). Segundo PATTEN \& GLICK (2002) a promoção do crescimento radicular ocasionado pelas rizobactéria promotoras de crescimento em plantas, possui relação com moléculas fitoreguladoras como as auxinas, as quais não possuem função hormonal para a bactéria, porém, as bactérias que apresentam interação com a planta produzem 0 fitormônio, presumindo-se que ele esteja envolvido com o crescimento de plantas.

A massa seca total (MST) e razão entre massa seca da parte aérea e massa seca de raízes (Razão MSPA/MSR) expressaram os resultados das médias que foram obtidas para a MSPA e MSR (Tabela 4). A MST mostrou maior acúmulo nas plantas onde as sementes foram tratadas com a rizobactéria associada à peliculização, mostrando a mesma diferença estatística observada para a MSPA e MSR, onde a combinação entre $B$. subtilis e polímero aplicados às sementes, promoveram maior acúmulo de MST nas mudas, com resultados estatisticamente superiores àquelas mudas em que as sementes foram somente peliculizadas. No que se refere à razão entre MSPA/MSR, houve igualdade estatística para todos os AGRARIAN ACADEMY, Centro Científico Conhecer - Goiânia, v.3, n.06; p. 59 2016 
tratamentos, destacando-se apenas que a maior razão foi obtida em mudas que receberam somente o biopromotor, e a menor razão no tratamento com biopromotor associado ao polímero.

TABELA 4 Massa seca da parte aérea (MSPA), massa seca total (MST) e razão entre massa seca da parte aérea e raízes (MSPA/MSR) de mudas de J. mimosifolia provenientes de diferentes tratamentos aplicados às sementes. Santa Maria-RS, 2016.

\begin{tabular}{|c|c|c|}
\hline \multicolumn{3}{|l|}{ Biopromotor } \\
\hline \multicolumn{3}{|c|}{ MSPA (g/planta) } \\
\hline & Com Polimero & Sem Polimero \\
\hline B. subtilis & $1,6117 \mathrm{Aa}^{*}$ & $1,4517 \mathrm{Ba}$ \\
\hline Testemunha & $1,4213 A b$ & $1,5520 \mathrm{Aa}$ \\
\hline CV (\%) & 8,14 & \\
\hline \multicolumn{3}{|c|}{ MSR (g/planta) } \\
\hline B. subtilis & $1,1090 \mathrm{Aa}$ & $0,8715 \mathrm{Ba}$ \\
\hline Testemunha & $0,8925 \mathrm{Ab}$ & 0,9657Aa \\
\hline CV (\%) & 9,91 & \\
\hline \multicolumn{3}{|c|}{ MST (g/planta) } \\
\hline B. subtilis & $2,7207 \mathrm{Aa}$ & $2,3232 \mathrm{Ba}$ \\
\hline Testemunha & $2,3138 \mathrm{Ab}$ & $2,5177 \mathrm{Aa}$ \\
\hline CV (\%) & 9,91 & \\
\hline \multicolumn{3}{|c|}{ Razão MSPA/MSR } \\
\hline B. subtilis & $1,4532 \mathrm{Aa}$ & $1,6657 \mathrm{Aa}$ \\
\hline Testemunha & $1,5924 \mathrm{Aa}$ & $1,6071 \mathrm{Aa}$ \\
\hline CV (\%) & 14,14 & \\
\hline
\end{tabular}

*Médias seguidas de mesmas letras, maiúsculas na linha e minúsculas na coluna, não diferem entre si pelo teste de Tukey a $5 \%$.

Os resultados obtidos neste trabalho evidenciam o potencial de $B$. subtilis como promotor de crescimento de mudas de espécies florestais. Cabe destacar que geralmente, a inoculação destes microrganismos ocorre diretamente no solo ou substrato, entretanto, a aplicação através das sementes pode servir como alternativa para a associação benéfica entre planta e biopromotor de crescimento. Outra constatação positiva deste trabalho remete a questão que envolve o uso de filmes poliméricos, os quais são comumente utilizados no tratamento de sementes de espécies não lenhosas, e que podem ser mais bem explorados quando se visa melhorar as qualidades morfofisiológicas das mudas. No caso, os resultados aqui expressados mostraram que o polímero beneficiou a ação de $B$. subtilis, tendo como hipótese a melhor fixação e prolongamento do tempo de contato do microrganismo com sementes, o que favoreceu a interação entre a rizobactéria e sistema radicular das mudas de $\mathrm{J}$. mimosifolia.

\section{CONCLUSÕES}

O tratamento de sementes de J. mimosifolia com B. subtilis e polímero promove o crescimento das mudas em viveiro.

A aplicação de $B$. subtilis associada a polímero em sementes de $J$. mimosifolia é uma técnica eficiente para a produção de mudas em viveiro. 


\section{REFERÊNCIAS}

ARAUJO, F. F.; HUNGRIA, M. Nodulação e rendimento de soja co-infectada com Bacillus subtilis e Bradyrhizobium japonicum / Bradyrhizobium elkanii. Pesquisa Agropecuária Brasileira, v. 34, n. 9, p. 1633-1643, 1999. Disponível em: http://www.scielo.br/scielo.php?script=sci_arttext\&pid=S0100-204X1999000900014. doi: 10.1590/S0100-204X1999000900014.

ARAUJO, F. F.; PEDROSO, R. A. B. Interação de Bacillus sp. com a rizosfera de três espécies de plantas forrageiras. Bioscience Journal, v. 29, n. 1, p. 152-158, 2013. Disponível

em: http://www.seer.ufu.br/index.php/biosciencejournal/article/view/11699/11982.

CARNEIRO, J.G.A. Doenças de Viveiro Florestal. Curitiba: Ministério da Educação e Cultura. UFPR. 1972. $31 \mathrm{p}$.

BRASIL. Ministério da Agricultura e Reforma Agrária. Instruções para análise de sementes de espécies florestais. Brasília: SNDA/CGAL, 2013. 97p.

CUNHA, J. F., ALFENAS, A.C.; SILVA, A.G.; BRANDÃO, I.J. Potencial de rizobactérias no crescimento de mudas de sibipiruna (Caesalpinia peltophoroides BENTH). Revista Árvore, v. 37, n. 2, p. 211-218, 2013. Disponível em: http://www.scielo.br/scielo.php?pid=S0100-

67622013000200002\&script=sci_abstract. doi: 10.1590/S0100-67622013000200002.

DINIZ, K.A.; OLIVEIRA, J.A.; GUIMARÃES, R.M.; CARVALHO, M.L.M.; MACHADO, J.C. Incorporação de microrganismos, aminoácidos, micronutrientes e reguladores de crescimento em sementes de alface pela técnica de peliculização. Revista Brasileira de Sementes, v. 28, n. 3, p. 37-43, 2006. Disponível em: http://www.scielo.br/scielo.php?script=sci_arttext\&pid=S0101-31222006000300006. doi: 10.1590/S0101-31222006000300006.

EMPRESA BRASILEIRA DE PESQUISA AGROPECUÁRIA - EMBRAPA. Sistema brasileiro de classificação de solos. 3. ed. Brasília: Embrapa Solos, 2013. 353p.

GUIMARÃES, A.M.; PAZ, I.C.P.; SANTIN, R.C.M.; PAULI, G.; SILVA, M.E.; SOUZA, R.V.; MASTUMURA, A.T.S.; SILVA, E.R. Utilização da rizobactéria Bacillus amyloliquefaciens na promoção de crescimento de alface (Lactuca sativa L.), em cultivo agroecológico. Cadernos de Agroecologia, Vol 8, No. 2, p. 1-14, 2013. Disponível em: http://www.icb.bio.br/utilizacao-da-rizobacteria-bacillusamyloliquefaciens-na-promocao-de-crescimento-de-alface-lactuca-sativa-I-emcultivo-agroecologico/.

HAASE, D. L.; ROSE, R.; TROBAUGH, J.. Field performance of tree stock size of Douglas-fir container seedlings grown with slow-release fertilizer in the nursery growing medium. New Forests, v. 2, n. 31, p. 1-24, 2006. Disponível em: http://link.springer.com/article/10.1007/s11056-004-5396-6. doi: 10.1007/s11056004-5396-6.

JUNGES, E.; SANTOS, R.F. dos; FINGER, G.; MUNIZ, M.F.B. Effect of priming and seed-coating when associate. Revista Ciência Agronômica, v. 44, n. 3, p. 520-526, 
2013. Disponível em: http://www.scielo.br/scielo.php?script=sci_arttext\&pid=S180666902013000300014. doi: 10.1590/S1806-66902013000300014.

JUNGES, E.; BASTOS, B.O.; TOEBE, M.; MULLER, J. PEDROSO, D.C.; MUNIZ, M.F.B. Restrição hídrica e peliculização na microbiolização de sementes de milho com Trichoderma spp. Comunicata Scientiae, v. 54, n. 1, p.18-25, 2014. Disponível em: https://comunicatascientiae.com.br/comunicata/article/viewFile/386/230.

LAZZARETTI, E.; MELO, I. Influência de Bacillus subtilis na Promoção de Crescimento de Plantas e Nodulação de Raízes de Feijoeiro. Jaguariúna: Embrapa Meio Ambiente, 2005. 21p. (Embrapa Meio Ambiente. Boletim de Pesquisa e Desenvolvimento, 28). Disponível em: http://www.cnpma.embrapa.br/download/boletim_28.pdf.

LEITE, H.A.C.; SILVA, A.B.; GOMES, F.P.; GRAMACHO, K.P.; FARIA, J.C.; SOUZA, J.T.; LOGUERCIO, L.L. Bacillus subtilis and Enterobacter cloacae endophytes from healthy Theobroma cacao L. trees can systemically colonize seedlings and promote growth. Applied Microbiology and Biotechnology, v. 97, n. 6, p. 2639-2651, 2013. Disponível em: http://link.springer.com/article/10.1007/s00253-012-4574-2. doi: $10.1007 / \mathrm{s} 00253-012-4574-2$.

LORENZI, H. Árvores Exóticas no Brasil: Madeireiras, ornamentais e aromáticas. Nova Odessa: São Paulo, 2003. 384p.

LUDWIG, E.J.; NUNES, U.R.; MERTZ, L.M.; SILVA, J.R.; NUNES, S.C.P. Vigor e produção de sementes de crambe tratadas com fungicida, inseticida e polímero. Científica, v. 42, n. 3, p. 271-277, 2014. Disponível em: http://www.cientifica.org.br/index.php/cientifica/article/view/464. doi: 10.15361/19845529.2014v42n3p271-277.

MANJULA, K.; PODILE, A. R. Increase in seedling emergence and dry weight of pigeonpea in the field with chitin-supplemented formulations of Bacillus subtilis AF 1. World Journal of Microbiology \& Biotechnology, v. 21, p. 1057-1062, 2005. Disponível em: http://link.springer.com/article/10.1007/s11274-004-8148-z. doi:10.1007/s11274-004-8148-z.

MAQBOOL, Z.; ASGHAR, H.N.; SHAHZAD, T.; HUSSAIN, S.; RIAZ, M.; ALI, S. ARIF, M.S.; MAQSOOD, M. Isolating, screening and applying chromium reducing bacteria to promote growth and yield of okra (Hibiscus esculentus L.) in chromium contaminated soils. Ecotoxicology and Environmental Safety, v. 114, p. 346-349, $2015 . \quad$ Disponível em: http://www.sciencedirect.com/science/article/pii/S0147651314002991. doi: 10.1016/j.ecoenv.2014.07.007.

MARQUES, E.; UESUGI, C. H. Avaliação de bactérias extremófilas facultativas na produção de fitomassa do híbrido "Urograndis" de eucalipto, a partir de sementes. Revista Arvore, v. 37, n. 1, p. 41-47, 2013. Disponível em: http://www.scielo.br/scielo.php?pid=S0100-

67622013000100005\&script=sci_abstract\&tIng=pt. doi: 10.1590/S010067622013000100005. 
MELO, A.P.C. De; SElEGUINI, A.; VElOSO, V. Da R. Dos S. Peliculização de sementes de tomate associada ao paclobutrazol. Bragantia, v. 73, n. 2, p.123-129, 2014. Disponível em: http://www.redalyc.org/articulo.oa?id=90831468005. doi: 10.1590/brag.2014.026.

MELO, A.P.C. De; SElEGUINI, A.; VELOSO, V. Da R. Dos S.; PEREIRA, J.M. Recobrimento de sementes de tomate com concentrações crescentes de polímero sintético. Ciência Rural, v. 45, p. 958-963, 2015. Disponível em: http://www.scielo.br/pdf/cr/2015nahead/1678-4596-cr-0103_8478cr20131335.pdf. doi:10.1590/0103-8478cr20131335.

MISSIO, E.L.; MORO, T. Tratamento de sementes na produção de mudas de angico vermelho. Caderno de Pesquisa, v. 28, n. 2, p. 38-51, 2016. Disponível em: https://online.unisc.br/seer/index.php/cadpesquisa/article/view/7127.

MOREIRA, A.L. de L.; ARAÚJO, F.F. de. Bioprospecção de isolados de Bacillus spp. como potenciais promotores de crescimento de Eucalyptus urograndis. Revista Árvore, v. 37, n. 5, p. 933-943, 2013. Disponível em: http://www.scielo.br/scielo.php?script=sci_arttext\&pid=S0100-67622013000500016. doi: 10.1590/S0100-67622013000500016.

PATTEN, C.L.; GLICK, B.R. Role of Pseudomonas putida indol-acetic acid in development of the host plant root system. Applied and Environmental Microbiology, v.68, n.11, p.3795-3801, 2002. Disponível em: http://aem.asm.org/content/68/8/3795.short. doi: 10.1128/AEM.68.8.3795-3801.

PEDROSO, D.C.; MUNIZ, M.F.B.; TUNES, L.M.; MULLER, J.; JUNGES, E.; DUTRA, C.B. Qualidade de sementes de cenoura armazenadas após recobrimento com fungicida, pó biológico e polímero. Bioscience Journal, v. 30, n. 2, p. 746-756, 2014.

Disponível

em: http://www.seer.ufu.br/index.php/biosciencejournal/article/view/19788/15235.

RAASCH, L. D.; BONALDO, S. M. Bacillus subtilis: enraizamento e crescimento de miniestacas de eucalipto em Sinop, norte de Mato Grosso, Brasil. Bioscience Journal, v. 29, n. 1, p. 1446-1457, 2013. Disponível em: http://www.seer.ufu.br/index.php/biosciencejournal/article/view/15179. Acesso em 03 de novembro de 2016.

SAMPAIO, T.; SAMPAIO, N. Recobrimento de Sementes. Informativo ABRATES, v. 4, n. 3, p. 20-52, 1994.

SANTOS, R.M.; RIGOBELO, E.C. Uso de Bacillus subtilis e Bacillus licheniformis na promoção de crescimento de mudas pré-brotadas de cana-de-açúcar. Ciência \& Tecnologia, $\quad$ v. $8, \quad$ p. 1-5, 2016. Disponível em: http://www.citec.fatecjab.edu.br/index.php/files/article/viewFile/800/pdf.

SIVASAKTHI, S.; KANCHANA, D.; USHARANi, G.; SARANRAJ, P. Production of Plant Growth Promoting Substance by Pseudomonas fluorescens and Bacillus subtilis Isolates from Paddy Rhizosphere Soil of Cuddalore District, Tamil Nadu, 
India. International Journal of Microbiological Research, v. 4, n. 3, p.227-233, 2013. Disponível

em:

http://s3.amazonaws.com/academia.edu.documents/32023458/Saranraj42.pdf?AWS AccessKeyld=AKIAJ56TQJRTWSMTNPEA\&Expires $=1478266320 \&$ Signature $=R 2 C 2$ 4dtWhIPYw\%2BzeHa3JYmLEeY4\%3D\&response-contentdisposition=inline\%3B\%20filename\%3DProduction_of_Plant_Growth_Promoting_Su b.pdf. doi: 10.5829/idosi.ijmr.2013.4.3.75171.

SZILAGVI-ZECCHIN, V.; MÓGOR, A.F.; RUARO, L.; RODER, C. Crescimento de mudas de tomateiro (Solanum lycopersicum) estimulado pela bactéria Bacillus amyloliquefaciens subsp. plantarum FZB42 em cultura orgânica. Revista de Ciências Agrárias, v. 38, n. 1, p. 26-33, 2015. Disponível em: http://www.scielo.mec.pt/scielo.php?script=sci_arttext\&pid=S0871-

$018 \times 2015000100005$.

TAYLOR, A. G.; GRABE, D.F.; PAINE, D.H. Moisture content and water activity determination of pelleted and film-coated seeds. Seed Technology, Zurick, v. 19, n. 1, p. 24-32, $1997 . \quad$ Disponível em: http://www.jstor.org/stable/23433247?seq=1\#page_scan_tab_contents.

TEIXEIRA, D. A.; ALFENAS, A.C.; MAFIA, R.G.; FERREIRA, E.M.; SIQUEIRA, L.; MAFFIA, L.A.; MOUNTEER, A.H. Rhizobacterial promotion of eucalypt rooting and growth. Brazilian Journal of Microbiology, v. 38, n. 1, p. 118- 123, 2007. Disponível em: http://www.scielo.br/scielo.php?script=sci_arttext\&pid=S151783822007000100025. doi: 10.1590/S1517-83822007000100025.

TRENTINI, P.; VIEIRA, M.G.G.C.; CARVALHO, M.L.M.; OLIVEIRA, J.A.; MACHADO, J.C. Peliculização: desempenho de sementes de soja no estabelecimento da cultura em campo na Região de Alto Garças, MT. Ciênc. agrotec, v. 29, n. 1, p. 84-92, 2005. Disponível em: http://www.scielo.br/pdf/cagro/v29n1/a10.pdf. 